\title{
RESPUESTA A MANUEL ATIENZA
}

\author{
Tomás-Ramón Fernández \\ Universidad Complutense de Madrid
}

Querido Manuel:

Madrid, 30 de enero de 2001

Acabo de recibir tu carta con los comentarios al nuevo libro de Nieto y al diálogo epistolar que con él mantuve poco tiempo antes y dejo a un lado los «papeles» que inundan mi mesa de trabajo para intentar contestarla sin más demora, ya que en este oficio nunca se puede estar seguro de que mañana estés más libre que hoy.

Ceñiré mi respuesta a los aspectos concretos que me conciernen directamente, ya que en lo demás, es decir en la crítica a las tesis de Nieto, nuestro acuerdo es total.

Tienes razón cuando al comienzo apuntas que sería muy fácil eliminar nuestras discrepancias con un breve intercambio de razones. Te agradezco que así lo hayas pensado por la confianza que con ello me muestras.

Mi concesión inicial a Nieto acerca de la concepción de la ley como simple directriz, «flecha que indica el rumbo a seguir», etc., se explica en el contexto de un diálogo que quiso ser desde el principio tan espontáneo como lo hubiese sido una conversación personal. Por lo demás, me pareció que tenía que acercarme a él todo lo posible y «entrar en la distancia», como se dice en el lenguaje pugilístico, ya que, de otro modo el «combate» hubiera resultado tan imposible como el de dos boxeadores que se limitan a girar el uno frente al otro, amagando constantemente pero tan lejos que no pueden alcanzarse. En un debate forense no lo hubiera hecho, como es natural, y en una confrontación académica más formal hubiera precisado, sin duda, como tú lo haces en tu carta, que esta concepción de la ley es sólo aplicable a unos concretos tipos de normas, pero no a todas. Es ésta una lección que terminé de aprender en vuestras «piezas del Derecho» y que tengo bien presente, pero tenía que aceptar el intercambio en ese terreno, so pena de frustrar el debate o hacerlo demasiado «frío» para el público al que iba a dirigirse.

En lo que se refiere a la afirmación que en mi diálogo con Nieto hago de que en treinta años de ejercicio profesional como abogado sólo he en- 
contrado un caso en el que, con toda sinceridad, no he llegado a tener claro cuál era la respuesta correcta, tengo para mí que, si pudieras ver un día los papeles del asunto, tu perplejidad sería al final semejante a la mía. En el libro hube de simplificar mucho el supuesto, ya que, de otro modo, el relato hubiese sido muy aburrido, amén de requerir más espacio de lo que una carta permitía.

No creo que la clave pudiera estar en la «catástrofe» para la Hacienda a la que aludo, expresión ésta relativa al mayor coste de una de las posibles interpretaciones un tanto exagerada, especialmente en estas fechas en las que una nueva sentencia, esta vez de la Audiencia Nacional, ha venido a sacudir el ya de por sí agitado escenario jurídico-político con un condena que, de confirmarse, obligaría al Estado a pagar cientos de miles de millones de pesetas a los funcionarios. Aquella «catástrofe» era cien veces menor.

Mi dificultad para encontrar en aquella ocasión una solución correcta y sólo una desde una perspectiva imparcial (como abogado me bastaba atenerme al tenor literal de la norma y a las dos Sentencias del Tribunal Superior de Justicia de Madrid que habían optado ya por la interpretación literal) venía, me parece, de que la norma reglamentaria a aplicar estaba sencillamente mal construida, muy probablemente porque los grupos de países a los que habían de aplicarse los coeficientes correctores destinados a compensar el diferente tipo de cambio y el también distinto coste de la vida no eran coherentes e incluían países poco homogéneos entre sí. A causa de ello, tanto si los dos coeficientes correctores se multiplicaban (tesis de la Administración), como si se sumaban (tesis de los recurrentes), los resultados eran estridentes en muchos casos.

Con todo, el hecho de que en treinta años de ejercicio profesional sólo en un caso me haya resultado imposible llegar a saber a qué atenerme, desde una perspectiva estrictamente objetiva, ya es suficientemente significativo. La excepción confirma la regla.

Voy con el tema de la técnica jurídica, al que me sería más cómodo dejar de referirme porque son tantos y tan generalizados los recelos y prejuicios que suscita que no consigo nunca hacerme entender. Tratándose de ti no hay mayor problema porque me conoces ya bastante bien y sabes cómo pienso y siento el Derecho y, por lo tanto, cómo acostumbro a hacerlo, pero a quienes no me conocen mis alegatos en favor de la técnica jurídica suelen llevarles al convencimiento de que soy un «tecnócrata». Tengo ya bien comprobado también que la crítica tópica a la técnica ofrece siempre una cómoda respuesta al que no se siente capaz de discutir en ese terreno y le proporciona una salida airosa que, además, suele merecer el aplauso del auditorio, que, normalmente, por poco técnico tira también a «progre», que es más cómodo y más lucido. 
Yo no me tengo en absoluto por tecnócrata, pero sí por un buen técnico, que es cosa muy distinta. Sé muy bien que el Derecho no es sólo técnica, pero sé también que no puede hacerse bien si se carece de ella. De ahí mi empeño en que las discusiones se desarrollen siempre sin olvidar la dimensión de la técnica jurídica. En otras palabras: una cosa es la condición y otra el modo; no son condiciones en sentido técnico las llamadas conditiones iuris, que se limitan a repetir las exigencias y requisitos previstos en las normas aplicables al caso; hay condiciones suspensivas y condiciones resolutorias, las condiciones imposibles anulan la obligación que de ellas dependa, etc. Y así se podrían enunciar miles de conceptos, decantados a lo largo de los siglos, que son tan precisos y exactos como la fórmula del ácido sulfúrico.

No todos los conceptos son tan precisos y están tan depurados, obviamente. Lo que yo llamo la técnica jurídica es un saber obtenido gracias al esfuerzo colectivo de las generaciones de estudiosos y prácticos del Derecho que se han sucedido a lo largo de dos mil años, saber que está sujeto, además, a un proceso permanente de revisión y ajuste que va depurando el contenido de cada concepto y cada pieza del sistema. Como es un saber histórico la solidez y fiabilidad de cada uno de esos conceptos tiene que ver mucho con su antigüedad, lo mismo que la consistencia de un terreno depende de la edad geológica de sus diferentes capas.

La consistencia de los conceptos jurídicos es -repito- distinta. Puede, incluso, ser escasa cuando se trata de conceptos que están en período de solidificación todavía, pero es enorme, tanta -insisto- como la fórmula del ácido sulfúrico, en otros muchos casos, de los que son buen ejemplo, me parece, los que más atrás he citado a propósito de las condiciones. Los primeros ofrecen mucho margen para la discusión y, por supuesto, para la manipulación también, pero ese margen va disminuyendo proporcionalmente a medida que crece la consistencia del concepto en juego y llega un momento, incluso, en que prácticamente desaparece.

En otras palabras: hay tesis que no se pueden sostener, que nadie que sepa lo que hay que saber puede sostener. Yo «no puedo» sencillamente sostener determinadas posiciones como abogado, por mucho que le interesen a mi cliente, porque ni siquiera «tengo» palabras con que hacerlo. Tampoco «puedo» sostener lo contrario de lo que tengo escrito y publicado, a menos que aporte nuevas razones, que habrán de ser muy serias además, en pro de mi nueva opinión, que, a falta de este «plus» de razonamiento, no sería creíble sencillamente y carecería de todo poder de convicción. Y lo mismo un Tribunal, que está «atrapado» por su propia doctrina anterior, de la que «no puede» apartarse como no exhiba muy buenas razones. 
La técnica jurídica «sujeta» y limita la discrecionalidad y el arbitrio, en una medida ciertamente menor que la lógica formal, respecto de la cual se encuentra en un escalón inferior, pero con parecida eficacia.

La alusión que hago en el libro a estos tres estadios -lógica formal, técnica jurídica y reglas de la argumentación-, no debe entenderse, como es natural, en el sentido en el que la toma Nieto, de cuya objeción tú te haces eco. Argumentar hay que hacerlo en todos los casos, como es obvio. Si yo separo artificialmente, a efectos dialécticos, esos tres estadios es solamente para mostrar que en el proceso argumental tienen una eficacia decreciente, en el bien entendido, sin embargo, que los tres la tienen y mucha o, dicho de otro modo, que la de la técnica jurídica está sólo a un paso de la de la lógica formal y la de las reglas de la argumentación, que a Nieto le parecen inanes, a dos pasos, no a mucho más.

Creo que me explico o, por lo menos, que tú me entiendes. Voy a ponerte un ejemplo vivido: yo fui abogado en el famoso «juicio de la construcción» de Burgos de un empresario, a quien entonces no conocía y a quien hoy tengo el mayor aprecio y considero buen amigo porque es una excelente persona, al que la Audiencia Provincial condenó a seis años de prisión por un supuesto delito de falsedad de documentos públicos y privados por estimar que había alterado la situación de una parcela que no tenía más que un solo lindero fijo, ya que se segregó de una finca matriz con la que vino a lindar por los tres vientos restantes.

Si los magistrados de la Audiencia Provincial -y luego los de la Sala Segunda del Tribunal Supremo que confirmaron su sentencia- hubieran conocido las técnicas propias de nuestro Derecho Urbanístico no hubieran podido apreciar la existencia de delito alguno, ya que, aun dejando de lado la imprecisa descripción registral de la parcela (ésta venía a ser como una cortina que corre a lo largo de su guía -el único lindero fijo- y que puede estar, por lo tanto, en cualquier punto de ella), se hubieran dado cuenta de que la supuesta alteración de la situación de la misma era sencillamente absurda habida cuenta de que, dentro de una misma unidad de actuación, todos los terrenos tienen la misma edificabilidad cualquiera que sea su posición. «Mover» artificialmente la parcela (correr la cortina) no tiene el más mínimo sentido, por lo tanto, ya que la edificabilidad correspondiente es siempre la misma; el resultado de multiplicar la superficie de la parcela por el índice de edificabilidad asignado por el plan a la unidad. Sólo si es para «sacar» la parcela de su unidad y llevarla a otra unidad contigua con un índice de edificabilidad mayor, cabe pensar en la comisión de un delito. En otro caso es sencillamente impensable la comisión voluntaria de la alteración documental de la situación de la parcela, muy especialmente cuando el propietario de la misma era un empresario experimentado, que había construi- 
do ya miles de viviendas en una larga carrera profesional desarrollada siempre en la propia ciudad, y, además, un Arquitecto técnico que conocía perfectamente el ordenamiento urbanístico y el Plan General de la ciudad.

Pues no hubo manera de evitar la condena, porque para que haya diálogo es imprescindible que quienes hablan utilicen el mismo lenguaje.

¿Comprendes ahora el porqué de mi insistencia en la importancia de la técnica jurídica? En treinta años me he encontrado muchas veces, muchísimas, demasiadas, con esos «diálogos de sordos». Tú, como teórico del Derecho, te vienes esforzando en trabar un diálogo científico con nosotros, los dogmáticos, porque crees, con toda razón, que sin él vuestro esfuerzo corre el riesgo de ser estéril. Yo, como jurista dogmático, hago lo propio enfatizando la importancia de la técnica jurídica porque sé por experiencia que es imprescindible elevar su nivel, que es, en general, muy bajo si se toma como referencia el colectivo entero de abogados y de jueces. La técnica jurídica no puede, desde luego, resolverlo todo. La advertencia es absolutamente banal. Sí puede, en cambio, resolver la gran mayoría de los problemas cotidianos.

No faltará quien piense que mi actitud es soberbia, arrogante o pretenciosa. Me da igual. Seguiré insistiendo en ello, aunque me lleven los demonios cada vez que oigo decir que la técnica no es neutral. Sé muy bien que con el gas se puede proporcionar calefacción y también la «solución final», pero no acepto de ningún modo que con ese argumento tópico se pretenda despachar sin más el asunto. Mientras lo hagamos así, estaremos aplazando la solución de muchos problemas que la tienen y malgastando un tiempo precioso para esforzarnos en enfocar mejor aquellos que, no teniéndola en la misma medida o, quizás, en ninguna otra, admiten, en cambio, una mayor y mejor aproximación.

Hay un apunte en mis cartas a Nieto, que en la tuya no has comentado, sobre el que me gustaría insistir. Me refiero a lo que llamo el «escenario procesal». Me parece importante llamar la atención sobre esto, porque tiene que ver mucho con el problema de la única solución correcta y también con el de la técnica jurídica y con el de la argumentación y creo que los teóricos del Derecho no le prestáis la atención que requiere. Cuando os proponéis un caso, tomado incluso de la realidad, sois, me parece, demasiado maximalistas o, si quieres, demasiado ambiciosos. Buscáis, ni más ni menos, la solución, en lugar de limitaros a indagar «la solución del caso tal y como se ha planteado».

Lo que quiero decir es que los problemas jurídicos nunca se plantean en abstracto. Surgen en la realidad, entre fulano y mengano, y se desarrollan de determinada manera y no de otra, en unas circunstancias concretas y no en otras distintas. Su discusión se produce en un proceso dado en el que se 
cruzan entre los abogados de las partes unos ciertos argumentos, más afortunados o menos. Podría ser de otro modo, en otras circunstancias, con otros abogados y manejando otras razones..., pero es como es y sobre esa concreta base es como ha de buscarse y obtenerse la respuesta correcta al conflicto así planteado.

Esto es bastante más fácil que buscar la respuesta correcta, en ese sentido más abstracto en el que vosotros acostumbráis a hablar. Está bastante más a nuestro alcance también, porque no se trata de hallar la solución justa, sino sólo la solución procedente en este concreto caso. La presión es menor cuando se busca la paz que cuando se busca la justicia. Nos conformamos más pronto y mejor, aunque la sentencia sea desfavorable, si de antemano hemos aceptado que lo que del proceso y de los jueces podemos obtener es la paz. Sabíamos que no teníamos el 100\% de razón, porque, de otro modo, difícilmente se hubiera producido el conflicto (hay, por supuesto, muchos pleitos que se provocan o se sostienen a sabiendas de que no se tiene ninguna razón, simplemente por demorar un pago inevitable, por obtener del tiempo alguna otra ventaja e, incluso, por agotar al adversario cuando éste esté más débil y forzar el compromiso), y, como lo sabíamos, nos resignamos al ver que la sentencia ha terminado por dar mayor peso a las razones del contrario. Exigimos sólo que la sentencia que así decide en contra nuestra haya tenido en cuenta nuestras razones y que se haya esforzado en demostrar que las de nuestro adversario eran mejores. Nunca nos convencerá del todo, naturalmente, pero sólo nos indignará en el caso de que deje de lado nuestros argumentos caprichosamente o acepte los del contrario sin justificar por qué lo hace.

Eso es, al menos, lo que a mí me ocurre, como abogado, cuando recibo la sentencia de un asunto en el que he intervenido y, más o menos, lo que piensa también el cliente en su interior, aunque de labios afuera diga siempre que le han hecho una faena.

Es en este sentido, pensando que así se desarrollan las cosas en la realidad y que ésa es, en fin, la función que realmente, valga la redundancia, cumple en la sociedad el Derecho, el proceso y el aparato judicial, como debe entenderse lo que en mis cartas digo de la paz como objetivo de todo ello.

Eso no supone que desconozca la dimensión moral del asunto. Simplemente intento situarme en un plano más abajo, más a mi alcance, más a mi medida, más modesto en una palabra, en el que sea posible ir cosechando algún pequeño éxito de cuando en cuando y no continuas decepciones. Por maximalista mi amigo Alejandro ha llegado al final de su carrera académica frustrado y dolorido. 
Pero, en fin, de todo esto habría mucho que hablar y de un solo golpe no es posible soltarlo todo. Sería una suerte que pudiéramos conversar seguido y con más frecuencia, pero también aquí las cosas son como son.

Pongo, pues, punto final, tanto más cuanto que hace sólo un instante sonó el teléfono y eras precisamente tú para decirme que este sábado te marchas a Estados Unidos. Que tengas una feliz y fructífera estancia allí. Grancias por la atención que me has prestado una vez más y un fuerte abrazo. 
$\triangle \quad$ DOXA $23(2000)$ 